\title{
ACHIEVING VALUE FROM ICT IN SMES: KEY MANAGEMENT STRATEGIES
}

\author{
K. Johnston, S. Parker, K.D. Tu, and F. Mosoval \\ Department of Information Systems, University of Cape Town, \\ Private Bag, Rondebosch, 7701
}

\begin{abstract}
ABSTRACS: ICT covers a broad range of fields in business and therefore makes ICT value difficult to simply define. The main factors that influence the use of ICT are therefore important to look at, as they give a good understanding of the how much influence the organisation has, on achieving value in its given context. The transformational model of ICT use was analysed to establish how SMEs in South Africa achieve business value from ICT and what management practices are most effective. Implications of the research are that management practices are an important factor that influences the value from ICT, and that the more management practices organisations implement, the greater the business value from ICT. Further findings of this study deduced that organisations that are more ICT aware, gain greater business value from ICT, with value achievement from ICT largely within the organisation's control. This paper concludes with recommendations for future research.
\end{abstract}

Keywords: Value, ICT, SME, management practices.

\section{INTRODUCTION}

Information Communication and Technology (ICT), the use of electronic computers and computer software to convert, store, protect, process, transmit, and retrieve information is a growing industry in South Africa [1, 2]. The South African Information Technology Industry Strategy (SAITIS), a national initiative, aims to build the ICT sector in South Africa to bring about sustainable economic growth, social upliftment and empowerment [1]. The major yardstick in ICT's future will be the value it delivers to the organisations $[3,4]$.

This paper aims to demystify the meaning of the value of ICT use and how best to derive benefit there from. After evaluating a number of studies such as those by Devaraj and Kohli (2006), Mirani and Lederer (1998), Solomons (2003) and Gregor et al (2004), it was decided to replicate the study conducted by the Australia government [5]. Most previous studies focused on large organisations in developed countries. Permission was obtained to use the Australian questionnaire, and this was then modified to suit a developing country such as South Africa's requirements. The questionnaire was further tailored to focus on Small and Medium Enterprises (SMEs) in the Western Cape of South Africa. No previous studies of this nature could be found which had been conducted in South Africa.

The purpose of this research was to replicate the Australian study, and base it in South African SMEs. The results of the study were evaluated against the results of the research done in Australia. This study focused on how SMEs in South Africa use ICT to achieve business value, and the strategies needed to realise value.

The transformational model of ICT was used as a basis to extract the relevant factors affecting the achieving of value from ICT. Each research question dealt with specific categories of the transformational model of ICT use. The objectives for this study were:

1. What are the current circumstances and settings in which ICT is implemented in SMEs?

2. How does the use of ICT contribute to the overall performance of SMEs?

3. What are the key differences between SMEs in the primary factors influencing the degree of business value?

4. What management practices are strongly associated with the recognition of benefits from ICT in SMEs?

5. Are there important differences in SMEs in the manner in which value is realised from ICT?

6. What are the key differences between Australia and South Africa (Western Cape) in achieving value from ICT?

\section{BACKGROUND LITERATURE}

\section{What is ICT Value?}

A dynamic technological and business environment has resulted in varied perceptions of value that can be derived from ICT. To aid in understanding value in ICT, a transformational model is used to show value arising from ICT used and the different influences on ICT value. 
Value is commonly associated with monetary worth. However due to the dynamic environment, no return on investment (ROI) formula or expected rate of return can be used to determine value. Value should be looked at more holistically to encompass not only a financial perspective. It should encompass aspects such as quality improvements, productivity gains, new services, and functions that contribute to the organisation's operational performance [6]. Value is also seen as the ability to participate in new markets, offer new products and services, to become more competitive, to operate more effectively and develop new capabilities [3].

Industry misunderstanding what value is and what value can be derived from using ICT is explained by the productivity paradox. The productivity paradox is the apparent failure of a substantial investment in information technology to contribute to productivity increase [5]. Aspects that can influence organisational productivity include the macroeconomic level, the industry level and the organisational level.

The determination of the causes of the productivity paradox allows for the identification and removal of obstacles, which would in turn lead to an increase in productivity. These dimensions are further strengthened by their utilisation in the transformational model of ICT use.

\section{ICT Use}

A model incorporating various ICT influences forms the basis of the study as it incorporates essential influences on ICT value. This model, the transformational model of ICT integrates several theoretical models which examine ICT impacts on organisational performance. The main factors that influence ICT and organisational performance are:

\section{The macro-economic level (external influences)}

External environmental factors such as government policies, global economic conditions, society and cultural issues, technology, and the availability and accessibility of infrastructure [5]. These factors are usually out of the organisation's control and can either inhibit or promote value.

\section{The industry level (Intra \& Inter-organisational influences)}

Characteristics of specific industry, such as its concentration, supply chain configuration and nature of products, shape how ICT can be used to create business value. Due to the varied characteristics of industries, how they respond to competition would therefore also vary and as a result this should also be considered.

The organisational level Influences (Intra \& Interorganisational influences)

Organisation structure, size and resources, together with the nature and type of applications influence the value derived from ICT [5]. Managing resources well (technological and human ICT resources) helps to achieve a temporary competitive advantage [7].

Organisational transformation serves as feedback to further changes in management practices, the application of ICT and other influences of ICT use [5]. It shows the significant time lags between investment and productivity gains, mentioned in the productivity paradox.

\section{The Macro-Economic Level}

\section{South Africa's current ICT Infrastructure}

Due to the influence of privatisation, innovation and development within the ICT sector, and the expansion into Africa, ICT is a growing industry in South Africa, and will continue to grow in the future [8].

The official regulator of the ICT sector is the Independent Communications Authority of South Africa (ICASA), which is responsible to the Minister for Posts, Telecommunications and Broadcasting”. The ICASA has engaged in extensive development programs to increase the communications infrastructure, especially in rural areas. Research shows the government spends 7 to 8 billion rand per year on ICT development and a significant share of Small Medium Enterprises (SME) is already involved in ecommerce [9].

The current ICT infrastructure in South Africa is strong in relation to other African countries, with plenty indications on future ICT investment and spending.

\section{Intra \& Inter-Organisational Influences}

Organisations can influence and control factors at the organisational level much easier than at the industrial or macro-economic level.

\section{Small Medium Enterprises (SMEs)}

SMEs make up 95 percent of the informal sector and up to 80 percent of the formal sector. Many inequalities exist in the informal business sectors which are being addressed by government and companies such as Microsoft investing into ICT and 
in communications infrastructures. Microsoft also suggests that ICT is essential to sustainable growth and development in South Africa. Addressing influences on ICT use in relation to SMEs will prove to be valuable to the future success of South Africa's economy [9].

The potential benefits achieved through ICT use can be categorized into four categories namely informational benefits, strategic benefits, transactional benefits and transformational benefits $[5,10]$.

Informational benefits are derived from access, quality and flexibility of information. Strategic benefits in turn consist of competitive advantage, alignment and customer relations. Transactional benefits consist of communication efficiency, systems development efficiency and business efficiency, and transformational benefits include organisational changes in business plans, models, structure, processes and skill levels.

\section{ICT-Specific Management Strategies}

Management strategies are developed to help organisations achieve set objectives and a vision for an organisation [11]. Management practices can significantly affect a company's performance [12]. Organisations that have more focused goals for ICT will perceive higher values and are more likely to engage in ICT related management practices [12]. ICT aware managers are more aware of the role of information technology and have a higher probability of achieving value [13].

To evaluate the business value of ICT, alignment between ICT and the business strategy is vital. To achieve alignment, organisation strategies, processes, and practices need to be effectively aligned to achieve companies' performance goals and objectives [3, 14]. Business strategy can enhance or diminish the impact of ICT and vice versa.

Creating business value is the responsibility of the entire organisation and management practices can be used to achieve synergy within all departments of an organisation. Nohria, Joyce and Roberson (2003a) conducted an extensive study on more than 200 management practices and formulated the $4+2$ formula' for sustained business success. Management strategies were into divided into primary (i.e. strategy, execution, culture and structure) and secondary management strategies (i.e. talent, motivation, leadership and mergers and partnerships).

Implementation of the $4+2$ formula increases the likelihood of sustaining higher business performance and should include all primary practices and at least two secondary practices [15].

\section{SUMMARY}

The benefits and value that can be achieved from ICT are essentially not only monetary values. ICT covers a broad range of fields in business and therefore makes value difficult to simply define. The main factors that influence ICT use are therefore important to look at as they give a good understanding of the how much influence the organisation has on achieving value in its given context.

The main factors that influence ICT are the macro-economic influences, industrial level influences and organisational level influences. The transformational model helps distinguish the broader perspective of influences on value.

Organisations cannot influence macro-economic and industrial level influences, other than understanding the influences which potentially could affect business performance. Therefore, South Africa's current ICT infrastructure was focussed on. This gave a better understanding to the macro-economic influences on ICT.

Organisations have full control over resources and other influences in terms of achieving value. However, a plan to achieve the organisation's objectives and good management strategies are needed. Therefore, ICT-specific management strategies were highlighted together with the importance of strategic alignment between ICT and the business strategy. The benefits derived from ICT use were categorised as informational, strategic, transactional and transformational benefits $[5,10]$.

\section{RESEARCH METHODOLOGY}

The research approach is explanatory (studies which establish causal relationships between variables) and not exploratory as the literature review has already shed some light on management practices and means of achieving value from ICT. Quantitative research best suites an explanatory approach. Quantitative research examines phenomenon through numerical representation of observations and statistical analysis thereof. Quantitative approaches assume the meaning of things, and measure and analyse amounts [16]. Data inevitably is transformed into a number; questions such as please rate the service on a scale of 1-5 are used. The Australian study used both quantitative and qualitative research. As for this study, only quantitative research was used due to time constraints and the difficulties associated with obtaining information from SMEs. The study was not affected by this since qualitative research was used by the Australian study to merely supplement their quantitative findings. The research philosophy is a 
positivistic philosophy. Precise and objective measures were used. These are best suited to quantitative data.

\section{Target Population}

The target populations for this research were SMEs from various industries in the Western Cape, South Africa. Due to time constraints, the whole of South Africa was not investigated. Therefore, when referring to South Africa, the Western Cape is implied. Fifteen industry categories were used in the Australian research. The list of industries is available from the authors upon request

The three highest industry responses were used in the analysis, as a result of the response rate being unexpectedly low. These industries were agriculture, forestry and fishing, retail trade and manufacturing industries. The other industries were categorised as other industries. The primary focus was on the size of the organisations rather than its industrial sector.

\section{Sample Selection}

Since a certain percentage of the SMEs are located in rural parts of the Western Cape, it is difficult to establish the exact target population. Therefore, the Cape Town Regional Chamber of Commerce and Industry (2005) was used to select the sample of SMEs in the Western Cape. The chamber has more than 4500 organisations all based in the Western Cape.

A total number of 2000 e-mails were sent to the respondents. The respondents were selected according to the number of employees in the organisation (1-50 for small organisations and 50-200 for medium organisations). The response rate was very low and therefore the sample size was much smaller than expected. A total number of 64 responded to the survey but only 56 responses were used in the final data analysis. It took approximately a month for all the respondents to reply to the surveys. Eight surveys were not used due to either the survey being incomplete or the number of employees exceeding 200.

\section{Data Collection}

The survey instrument was used as the primary data collection instrument. The data collection instrument was taken from the Australian Government research and adjusted to suite the South African context.

The survey instruments were distributed to the described subjects via e-mail. This method was the least costly and most time efficient. The survey instruments were also adjusted so that it can be easily answered in digital form. Ensuring the confidentiality of e-mails sent to each SME, the e-mails were sent by BCC (Blind Carbon Copy) which is a method of hiding the list of recipients of an e-mail from the receiving recipient.

\section{The Survey Instrument}

The survey instrument was developed by the Australian Govemment together with 27 organisations within Australia. It was developed through rigorous review of relevant theoretical models, related survey instruments, previous research outcomes and focus group consultations with executives and senior ICT managers. The same instrument survey was used in this study. As mentioned, the Australian Government granted permission to use their survey. The survey instrument was modified and shortened in the attempt to increase response rates.

The survey instrument contained 31 questions, broken down into seven sections. Sections 1 and 2 addressed the first research question; section 5 addressed question 2, sections 4 and 6 question 3, section 4 question 4, sections 3, 4, 5 and 7 question 5 .

\section{Data Analysis}

Incomplete surveys were taken into account. Once the completed surveys were returned, they were captured. A quantitative approach is the focus of this research and therefore Microsoft Excel was used to capture the survey responses. The majority of the questions were based on a set list of answers and therefore each answer was given a numerical value. These numerical values were captured into a spreadsheet. This method of storing the data has many benefits such as making it possible to view patterns to responses easier and data manipulation quicker.

The majority of the analysis was done through descriptive statistics with frequency, mean and percentage tables, histograms, and correlation matrix tables. The statistical methods followed the Australia's study as close as possible in order to replicate their study as far as possible to ensure effective comparison between the two studies.

\section{RESULTS}

\section{ICT Usage Types}

Standard desktop, internet searching, email, electronic banking and electronic payments were observed to be the most common used ICT application across all the industry groupings. The minimum usage rate for these applications is $85 \%$.

Mobile devices and electronic sales are relatively low across all industries. The usage rates of mobile 
devices ranges from $14.29 \%$ for Manufacturing to $42.86 \%$ for Agriculture, Forestry and Fishing. The usage rates of electronic sales ranges from $12.5 \%$ for Retail to $54.14 \%$ for Agriculture, Forestry and Fishing. For the availability of public access websites, there is a high usage rate for all industries except in the Retail Trade which is only 50\%. Internal network applications have a high rate of usage for all industries except in the Retail Trade which also has a 50\% rate.

The use of ICT in respect to electronic purchasing and integrated processes, suppliers and customers vary across all the industry groupings. The lowest rate in integrated processes, suppliers and customers is $35.71 \%$ for Manufacturing and the highest rate is $71.43 \%$ in Agriculture, Forestry and Fishing. The lowest rate in electronic purchasing is $37.5 \%$ for Retail Trade.

\section{CT Management and Outsourcing}

External support was most frequently used across all organisations. Internal specialist ICT units and staff not specialising in ICT were used equally as frequent, but half as often as external support.

Retail Trade has 50\% for software development outsourced in the 'nil' percentage category. This is however inclusive of organisations who do not undertake software development at all and those who undertake software development in-house. It is interesting to note that the highest industry group score for the $81-100 \%$ range is $28.57 \%$.

Small organisations either outsource software development in large or small portions, with not much in between. More small organisations appear in the Nil category than do medium. The medium organisations have a much more even spread across the categories with most of the percentage of software development outsourced in the $1-20 \%$ range.

\section{ICT Expenditure - Decision Making}

Majority of the decision making on ICT expenditure are done by the CEO/Owner and then cross functional teams. Small organisations have a higher percentage $(84.4 \%)$ of CEO/Owner made decisions than medium enterprises (60.9\%). The next key decision maker for ICT expenditure was crossfunctional teams. For this category, medium organisations had a higher percentage (21.7\%) than small organisations (9.4\%).

The CEO/Owner is the key influential decision maker in ICT expenditure in all three industry groups. The ICT department is second most influential in Agriculture, Forestry and Fishing and Manufacturing, with cross functional teams being just as influential in Agriculture, Forestry and Fishing.
The study has found that pervasive ICT applications are extensively used across all organisations sizes and industries. However, the use of more advanced applications such as Mobile devices and Electronic sales are not commonly used, even in medium sized organisations.

ICT outsourcing of day to day support have been widely used in both small and medium organisations, with considerable variation. However, most of the day to day ICT support outsourced falls in the $1-40 \%$ range. This could be a result of the study focusing on SMEs.

Most outsourcing of software development falls in the $1-20 \%$ or $81-100 \%$ range extremes. This is especially true with small sized organisations. Medium organisations have a more even and wide spread of outsourcing.

Offshore outsourcing has not been taken up by organisations to a significant degree and the vast majority of organisations do not outsource offshore. There is also no significant difference between small and medium organisations in terms of outsourcing offshore.

In measuring the overall performance of SMEs and how ICT affects this, the value of ICT needs to be measured. The different benefits of ICT use were analysed and overall, the study indicated that ICT contributed positively to SME performance.

\section{The key differences between SMEs in the primary factors influencing the degree of business value}

Informational benefits were recognised as the benefit bringing the most value to SMEs. These included faster and easier access to internal and external information, more useful, accurate and reliable information and flexibility in the manipulation of content and format of information.

The least benefit from ICT use was derived from Organisational Transformation benefits in small organisations. Organisational transformation benefits included improved skill levels, new business plans and business models, expanded capabilities, and improved structure and processes.

The least benefit from ICT use was derived from Transactional benefits in medium organisations. Transactional benefits included operational and cost savings, supply chain management savings, staff cost savings, and improved business efficiency of employees, business processes, and financial resources despite them being easy to quantify in advanced.

This was synonymous with the Australian study and possible explanations for the lack of transactional benefits were that they were quickly achieved and therefore taken for granted (less salient to managers). 
Transactional benefits could also have been ignored as the focus was on 'innovations' in respect to achieving value from ICT (Gregor et al., 2004).

As small organisations placed more importance on investment drivers, perception on business value increased. For medium organisations, investment drivers were consistent in terms of deriving business value from them. This indicated that the impact on business value was not dramatically affected by the importance ratings of ICT investment drivers.

Another factor that affected the value from ICT is management practices. Business value is found to be the highest for organisations who always engage in management practices. All management practices are employed in small organisations. This resulted in increased business value. Medium organisations did not adopt all the management practices and achieved a lower business value. Therefore, the more management practices an organisation adopts, the greater the business value from ICT.

It is found that there are no significant differences between SMEs in relation to the two primary factors (ICT investment impetus and management practices). Generally, SMEs which find investment drivers to be important derive greater business value. If management practices are employed, business value is further increased.

The management practices that are strongly associated with recognition of benefits from ICT in SMEs

The strongest relationship between the management practices is the correlation between ICT integration (into existing business processes across key functional areas) and strategy planning (formal business and ICT strategic planning). ICT planning and strategic planning are the key management practices that most influence the business value in organisations.

ICT planning includes:

- Using a formal project management methodology

- Developing formal business cases for ICT investment

- Have a post-implementation reviews of ICT investments

Strategic planning includes:

- Engage in formal business strategic planning

- Engage in formal ICT strategic planning.

ICT planning and Strategic planning are the strongest practices associated with recognition of benefits from ICT.

\section{DISCUSSION}

The study has found pervasive ICT applications are extensively used across all organisations sizes and industries, with the exception of more advanced applications. Organisations which engaged in outsourcing showed relatively high levels of success with their outsourcing arrangements. More small organisations experienced unsuccessful outsourcing arrangements than medium ones. The study found that majority of the decision making on ICT expenditure is done by the $\mathrm{CEO} / \mathrm{Owner}$.

These findings affected the value from ICT use as they formed part of the 'organisational level influences' of the transformational model of ICT use.

\section{How the use of ICT contributes to the overall performance of SMEs}

The different benefits of ICT use were analysed and overall, the study indicated that ICT contributed positively to SME performance.

Research has shown that benefits are gained regardless of organisational size (Gregor et al., 2004) and this study found that the overall mean business value was similar for both small and medium organisations

\section{The key differences between SMEs in the primary factors influencing the degree of business value?}

There are no significant differences between SMEs in relation to the two primary factors (ICT investment impetus and management practices) influencing the degree of business value. SMEs who find investment drivers and management practices to be important derive greater business value from ICT.

\section{Management practices that are strongly associated with recognition of benefits from ICT in SMEs}

ICT planning and Strategic planning are the strongest practices associated with the recognition of benefits from ICT.

\section{Important differences between SMEs in the manner in which value is realised from ICT}

Certain valuable differences were found in SMEs in the manner in which value is realised and in the factors that influence business value. However, no crucial differences were found in terms of achieving value from ICT in small organisations relative to medium ones. 


\section{The key differences between Australia and South Africa (Western Cape) in achieving value from ICT}

Throughout the study, where possible, findings were compared with Australia in specifically allocated sections. Findings varied throughout, and more often than not, confirmed the Australian study.

\section{Final Summation}

Implications of the research are:

- Management practices are an important factor that influences the value from ICT.

- The more management practices organisations implement, the greater the business value from ICT.

- Organisations that are more ICT aware gain greater business value from ICT.

- 'Organisational level influences' were found to have significant influence on achieving business value from ICT. Organisations are in control of 'Organisational level influences'. Therefore, achieving value from ICT is largely within the organisation's control.

- The use of ICT contributed positively to organisation performance.

Organisation size did not have a significant influence on achieving value from ICT.

\section{REFERENCES}

1. SAITIS, 2006, South African ICT Sector Development Framework. [WWW document]. URL: http://www.dti.gov.za/saitis. 02 August 2006

2. Wesso, H., 2002, Western Cape Information and Communication Technology Sector Scan 2001. Cape Information Technology Initiative.

3. McKeen J.D and Smith H.A., 2004, Making IT happen, Critical Issues in IT Management, Wiley, USA, ISBN 0-470-85087-6.

4. Solomons, F., 2003, Bringing the benefits of ICT to Africa. NEPAD, Focus on Africa. June, 24. No. 5

5. Gregor, S., Fernandez, W., Holtham, D., Martin, M., Stern, S., Vitale, M and Pratt, G.,2004, Achieving Value from ICT: key management strategies, Department of Communications, Information Technology and the Arts, ICT Research Study, Canberra. ISBN 0642752907.

6. Brown, A., 2005, IS Evaluation in Practice. The Electronic Journal Information Systems Evaluation, 8, (3), 169-178.

7. Gurbaxani, V., Kraemer, K. and Melville, N, 2004, Information Technology and Organizational Performance: An Integrative Model of IT
Business Value. Center for Research on Information Technology and Organizations. University of California, Irvine.

8. Rowe, J., 2002, ICT Cluster Development: Cluster Spider, Structure and Gap Analysis. South African Informational Technology Industry Strategy Project. March 2002.

9. Wolf, S., 2001, Determinants and Impact of ICT Use for African SMEs Implications for Rural South Africa. Trade and Industrial Policy Stratagies, September, 2001.

10. Mirani, R. and Lederer, A.L., 1998, An Instrument for Assessing the Organizational Benefits of IS Projects. Decision Sciences, 29, (4), Fall.

11. Devaraj, S. and Kohli, R., 2006, Realizing Business Value of Informational Technology Investments: An Organizational Process. [WWW document]. URL http://scholar.google.com/ scholar?hl=en\&lr=\&q=cache:Jdq8SDvnCWsJ: www.nd.edu/ rkohli/issues/Kohli\%2520Devaraj\% 2520MISQE.pdf+value+of+information+technolo gy. 10 April 2006.

12. Tallon, P., Kraemer, K. and Gurbaxani, V., 2001, Executives' Perceptions of the Business Value of Information Technology: A Process-Oriented Approach. Center for Research on Information Technology and Organizations, 16 (4), pp. 137165.

13. Gurbaxani, V., Kraemer, K. and Tallon, P., 2001, Executives' Perceptions of the Business Value of Information Technology: A Process-Oriented Approach. Center for Research on Information Technology and Organizations.

14. Tallon, P.P., 2003, Using Flexibility to Enhance the Alignment between Information Systems and Business Strategy: Implications for IT Business Value. April, 2003.

15. Nohria, N., Joyce, W. and Roberson, B., 2003a, What Really works: The 4+2 Formula for Sustained Business Success. Harper Collins Publishers. ISBN: 00605-12784.

16. Blumberg, B., Cooper, D. R., and Schindler, P.S., 2005, Business Research Methods. Maidenhead: McGraw-Hill.

17. Daniel, E. and Ward, J., 2006, Benefits Management: Delivering Value from IS \& IT Investments. Wiley, USA, ISBN 0-470-09463-X.

18. Lucas, H.C. Jnr., 2005, Information Technology, Strategic Decision Making for Managers. Wiley, USA, ISBN 0-471-65293-8.

19. Nohria, N., Joyce, W. and Roberson, B., 2003b, $4+2=$ Sustained Business Success. Harvard Business School Working Knowledge, 81, (7). 